\title{
Scour patterns below pipelines and scour hole expansion rate
}

\author{
Y. Zhu, L. Xie \& X. Liang \\ College of Civil Engineering, Tongji University, Shanghai, China
}

\begin{abstract}
This paper presents the results of an experimental study on the onset of scour and the propagation of scour hole on the cross-section of a partially buried pipeline under a unidirectional current with uniform sediment. A specially designed device including a transparent pipeline with a mini underwater camera installed inside it is utilized to observe and record the whole scour process. The scour below the pipeline can be divided into an integral scour pattern and a partial scour pattern. In both patterns, the seepage force is the main cause of the onset of scour. However, the scour hole expansion process is driven by the seepage force in the integral scour pattern, while in the partial scour pattern it is driven by the bed shear stress. The effects of pipeline embedment, flow depth and the averaged flow velocity on the averaged cross-section expansion rate of the scour hole are also evaluated.
\end{abstract}

\section{INTRODUCTION}

The submarine pipelines laid directly on the seabed may be faced with scours beneath them due to severe working conditions. As the scour hole extends along the pipeline, pipeline span and sagging will occur, which will result in pipeline failure and thus serious economical and environmental disasters. Therefore, it is of great importance to understand the critical conditions of the onset of scour.

The scour beneath the pipeline starts from the onset of scour. When a pipeline laid on a horizontal sediment bed is faced with unidirectional current, the pressure difference between the upstream and downstream sides of the pipeline will lead to the seepage flow underneath it. If the pressure difference is excessive, piping will occur beneath the pipeline and cause the onset of scour. The researches on the onset of scour are numerous. Chiew (1990) reported the close link between the onset of scour and the pressure difference on two sides of the pipeline through physical experiments, and pointed out that the basic mechanism of onset of scour is the piping, a kind of seepage failure. Sumer et al. (2001) conducted a series of experiments with the help of an underwater camera. The results confirmed that the excessive seepage flow and the piping caused by it is the dominant attribution to the onset of the scour. The critical conditions of the onset of scour were also investigated for current and wave conditions respectively. Gao \& Luo (2010) established a coupling simulation model including both the main flow above the sea bed and the seepage flow inside it. The simulation results indicated that the maximum seepage gradient underneath the pipeline located at the downstream side, where the onset of scour started. Wu \& Chiew (2010) carried out a series of experiments on the effects of several parameters on the lateral propagation rate of scour hole (along the pipeline), finding that the development of pipeline span could be divided into two stages, namely a rapid and slack phase of development. Cheng \& Zhao (2010) established a three dimensional model for simulating the scour hole expansion in spanwise direction and discovered that the scour hole development is mainly caused by the flow velocity at the span shoulders. Zhou et al. (2011) carried out a series of experiments on three different types of soils in current and wave conditions. The result showed that the pore pressure responses to the current and waves were considerably different in different types of soil due to the variation in the properties of the soils. Kazeminezhad et al. (2012) presented an Eulerian two-phase flow model for the waveinduced scour beneath the pipeline and observed the tremendous sediment transport in the high turbulence intensity after the onset of scour.

Some other researchers focus on the scour hole development on the span shoulder. Hansen et al. (1991) investigated the longitudinal development of the scour hole, namely the scour hole propagation along the axis of the pipeline. It was found that the increase of pipeline embedment could dramatically reduce the scour hole propagation rate. Bijker et al. 
(1991) reviewed the start and development of pipeline free span and discussed several aspects of the pipeline span development, including the onset of scour, pipeline embedment, the scour hole propagation rate and the stopping criteria. Chen \& Cheng (2002) simulated the three-dimensional flow field around the span shoulder of a spanned pipeline in both laminar and turbulent flows. The results showed that significant shear stress concentration was formed around the span shoulder. The mechanism of the concentration was also discussed. Shen et al. (2013) and Shen et al. (2014) presented the results of computational fluid dynamics (CFD) simulations on the variation of seabed shear stress around submarine pipelines. The shear stress amplification factors including pipeline spanning and embedment, trench configuration, current/wave direction and current/wave properties were studied with 3D models.

However, most present documentations on the onset of scour put emphasis on the critical conditions of the piping phenomenon (Zang et al. 2009) and the flow field around the span shoulder after the onset of scour (Chen \& Cheng 2002, Cheng et al. 2009, Yeganeh-Bakhtiary et al. 2011, 2013, Wu \& Chiew 2013); the process of onset of scour and the mechanism in this process are only seen in limited reports (Sumer et al. 2001). In this paper, a series of experiments are designed for investigation on the onset of scour and temporal development of scour hole on the cross-section of a partially buried pipeline under a unidirectional current with uniform sediment. A specially designed device which includes a transparent pipeline and a mini underwater camera installed inside the pipeline is utilized in the experiments. The process of the scour is observed directly from inside of the pipeline; the mechanism of the process is analyzed and the parametric effects on the scour hole propagation rate on the cross-section of the pipeline are also studied.

\section{EXPERIMENT SETUP}

All the experiments are conducted in the Laboratory of Hydraulic and Harbor Engineering, Tongji University, Shanghai, China. The glass-sided flume (See Fig. 1a) is $50 \mathrm{~m}$ long, $0.8 \mathrm{~m}$ wide and $1.2 \mathrm{~m}$ deep. A metal fence is installed at the entrance of the flume to stabilize the current and keep the velocity distribution uniform across the flume width. The current is generated by a pumping system with an electronic speed controller which is able to generate steady current up to $0.7 \mathrm{~m} / \mathrm{s}$ in water depth of $0.5 \mathrm{~m}$. A 2.7 $\mathrm{m}$ long, $1 \mathrm{~m}$ deep sediment recess is located $20 \mathrm{~m}$ downstream from the entrance of the flume. The bottom of the flume, the sides and bottom of the sediment recess are all made of concrete and are impermeable. The center of the pipeline is $1.2 \mathrm{~m}$ from the upstream end of the sediment recess (See Fig. 1b).
The medium grain size of the uniform sand used in the experiment $d_{50}=0.16 \mathrm{~mm}$, and the geometric standard deviation $\sigma_{\mathrm{g}}=\left(d_{84} / d_{16}\right)^{1 / 2}=1.4$. The critical velocity for the incipient motion of the sediment is $0.226 \mathrm{~m} / \mathrm{s}$ when the flow depth is $0.4 \mathrm{~m}$.

The ambient depth averaged flow velocity is monitored by a Nortek Vectrino 3D acoustic velocimeter, which is set $10 \mathrm{~m}$ downstream to the pipeline. According to Qiu (1999), the depth averaged velocity equals to the velocity at about 0.6 times water depth from water surface in open channel flows so the sampling point is fixed at $0.6 z_{0}$ from the flow surface. The flow velocity reaches the required value in about 110 to 120 seconds in all cases.

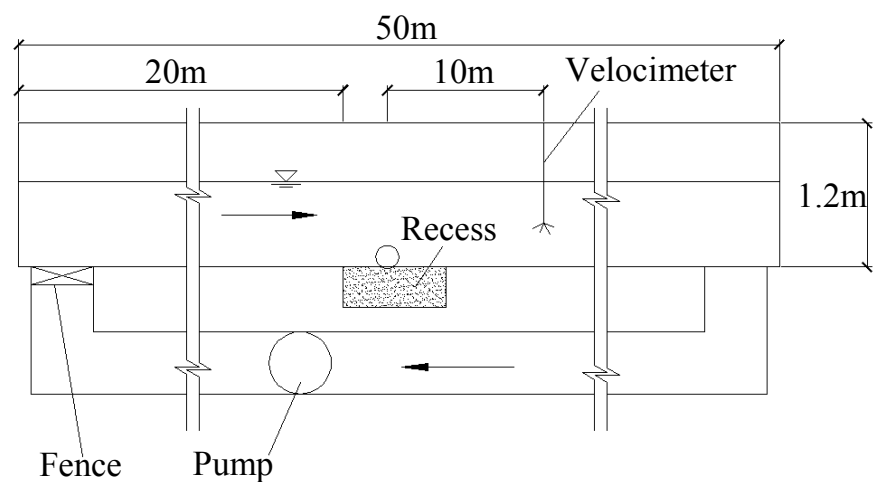

a) Flow Flume

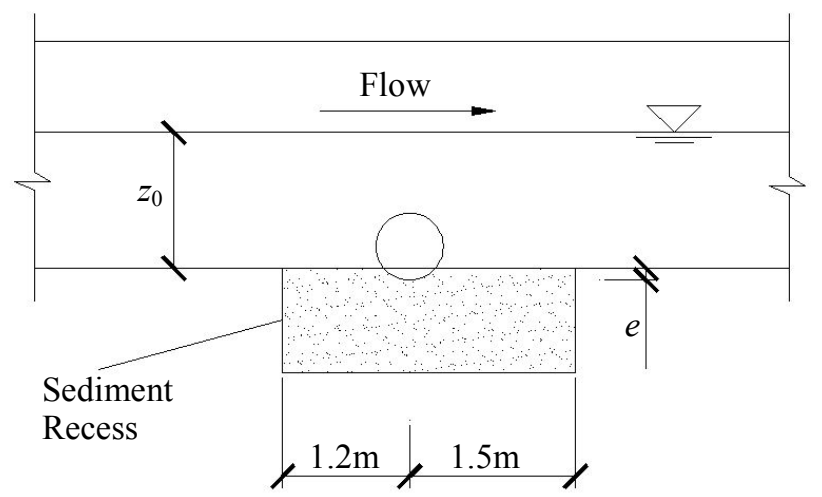

b) Test section

Figure 1. Side view for the experiment setup (Not in scale). $z_{0}$ is the flow depth; $e$ is the pipeline embedment.

Figure 2 shows the cross-section sketch of the experiment setup. A transparent pipeline made of plexiglass which is $11 \mathrm{~cm}$ in diameter and $80 \mathrm{~cm}$ in length is used in the experiment. The pipeline is rigidly fixed with two jackscrews on both ends. A mini underwater video camera is installed inside the pipeline. Both ends of the pipeline are sealed to avoid sand deposition inside the pipeline, which may cause interference of the camera view. The camera is controlled with computer software and is able to take photographs and videos with a resolution of $640 \times$ 480 pixels. The frame frequency of the videos is 15 fps. A transparent plastic ruler with a minimum scale of $1 \mathrm{~mm}$ is stuck inside the pipeline within the view of the camera. The scour process can be observed through the camera and measured with the readings 
on the plastic ruler. A similar device was used by Raaijmakers et al. (2014) to investigate the scour around the offshore monopoles. Two ballast blocks are installed inside the pipeline to make the pipeline more stable in the experiment.

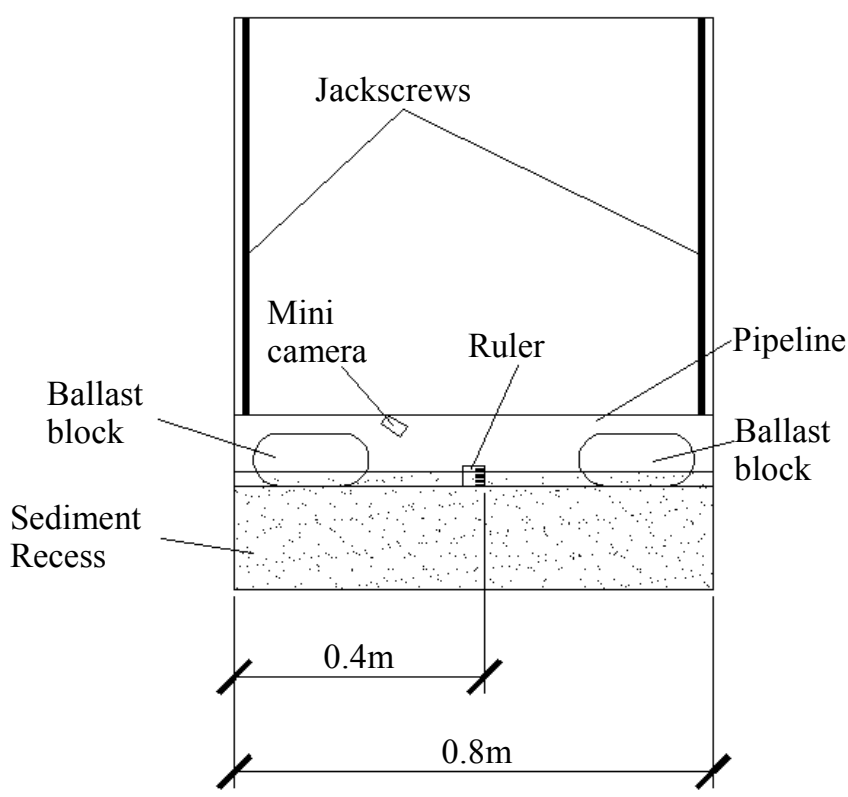

Figure 2. Cross-section view of the experiment setup (Not in scale)

The experiments can be divided into three parts, with each one focusing on the effect of one parameter, namely the embedment-diameter ratio, the relative flow depth and the depth averaged flow velocity (See Tab. 1). Only one parameter is changed within each group and all the others are kept constant. Experiment group 1 focuses on the effect of the embedment to diameter ratio on the expansion of the scour hole; group 2 the effect of relative flow depth and group 3 the effect of depth averaged flow velocity.

Table 1. Experiment conditions for the cases

\begin{tabular}{llllll}
\hline Group & Case & $e / D$ & $z_{0} / D$ & $\begin{array}{l}V_{0} \\
(\mathrm{~m} / \mathrm{s})\end{array}$ & Remarks \\
\hline \multirow{4}{*}{1} & 201 & 0.045 & 2.73 & 0.6 & Effect of \\
& 202 & 0.091 & 2.73 & 0.6 & pipeline \\
& 203 & 0.136 & 2.73 & 0.6 & embedment \\
\hline \multirow{4}{*}{2} & 204 & 0.182 & 2.73 & 0.6 & \\
& 205 & 0.045 & 2.73 & 0.4 & \\
& 206 & 0.045 & 3.64 & 0.4 & Effect of \\
& 207 & 0.045 & 4.55 & 0.4 & flow depth \\
3 & 208 & 0.045 & 5.45 & 0.4 & \\
& 209 & 0.045 & 3.64 & 0.2 & \\
& 210 & 0.045 & 3.64 & 0.3 & Effect of \\
& 211 & 0.045 & 3.64 & 0.4 & flow velocity \\
\hline \multirow{4}{*}{3} & 212 & 0.045 & 3.64 & 0.6 & \\
\hline
\end{tabular}

* $D$ is the pipeline diameter, $D=11 \mathrm{~cm} ; V_{0}$ is the depth averaged flow velocity; $e / D$ is the embedment to diameter ratio; $z_{0} / D$ is the relative flow depth.

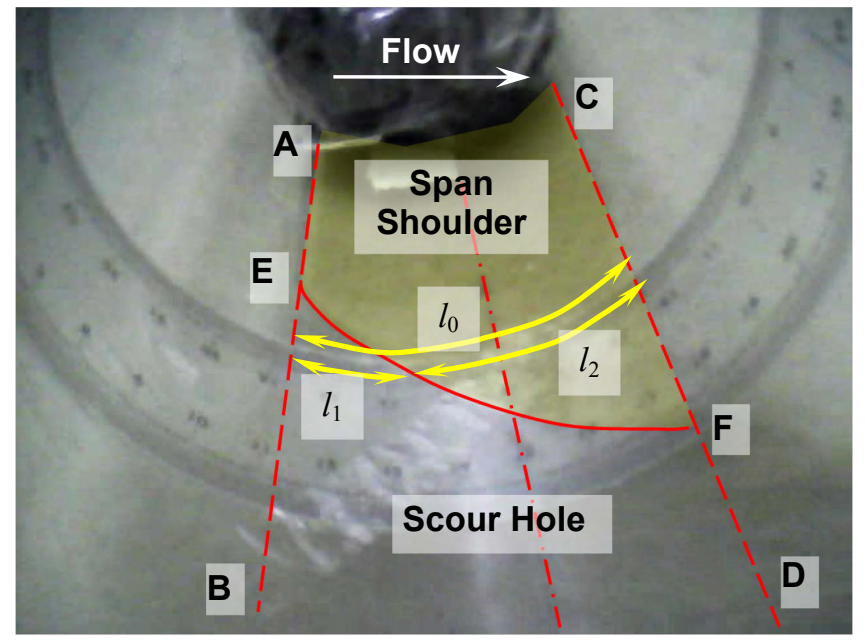

(a) Typical camera view

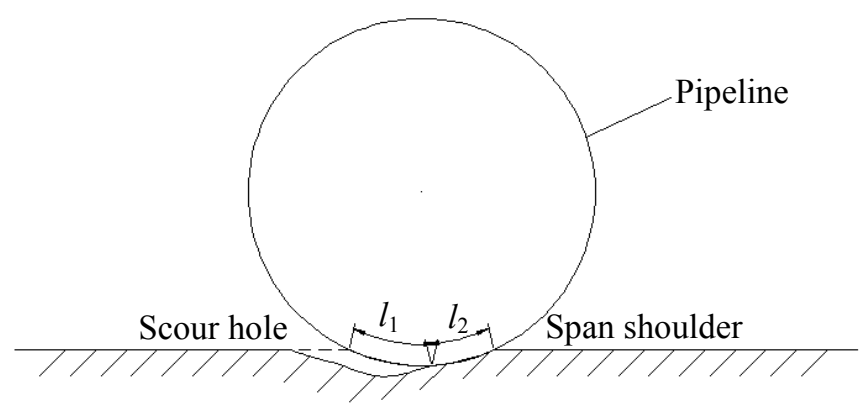

(b) Cross section sketch of $l_{1}$ and $l_{2}$

Figure 3. Typical view of the underwater camera

Figure 3 a shows a typical view of the underwater camera. In Figure 3a, the dot-dash line near the center is on the same vertical surface with the center line of the cylinder and the origin of the ruler aligns with it. The dotted line (AB and $C D$ ) is the interface of the buried parts of the pipeline and the surface of the sediment. The red solid line (curve EF) is the interface of the scour hole and the span shoulder (see the parts with the yellow shadowing). The minor arc on the section of the pipeline between the two dotted lines is called the embedment arc $\left(l_{0}\right)$. After the scour process starts, the scoured part in the embedment arc is called the scoured arc $\left(l_{1}\right)$, and the rest part is called the span shoulder arc $\left(l_{2}\right)$ (See Fig. 3b). According to the definition above, it can be attained that $l_{0}=l_{1}+l_{2}$. The cross-section expansion rate of the scour hole on the observed section is defined as:

$v_{s}=\frac{\mathrm{d} l_{1}}{\mathrm{~d} t}$

And the averaged cross-section expansion rate of the scour hole is defined as:

$v^{\prime}=\frac{l_{0}}{t_{0}}$

where $t_{0}$ is the total time used in the scour process on the observed section. The black block in the top middle of the view is the ballast block (See Fig. 3). 
All the frames of the video recordings obtained with the underwater camera are extracted with a media player one after another after the experiment. As is mentioned above, the frame frequency of the video is $15 \mathrm{fps}$, so the time interval between two successive flames is 1/15 seconds. The length of scoured arc $\left(l_{1}\right)$ is also read in every frame. With the recordings of $l_{1}$ values and the corresponding time values, the curve of scour hole temporal development in each case can be obtained.

\section{THE SCOUR PATTERNS UNDER THE PIPELINE}

With the variation of the pipeline embedment, the flow depth and the approach flow velocity, the scour pattern underneath the pipeline can be remarkably different. In this study, two different scour patterns are observed within the tested ranges of the three parameters, namely the integral scour pattern and the partial scour pattern.

\subsection{Process of the integral scour pattern}

The integral scour pattern occurs in case 205, 206 and 212. Figure 4 shows the frames of the video recorded in case 206, indicating the whole process of the scour. In case 206, the pipeline embedment depth is $0.5 \mathrm{~cm}$, and the length of the embedment arc should be $4.72 \mathrm{~cm}$, according to the geometric relationship. Thus, the readings of the interface line $A B$ and $\mathrm{CD}$ on the ruler should be $4.72 / 2=2.36 \mathrm{~cm}$. In Figure $4 \mathrm{a}$, the actual reading is about $2.4 \mathrm{~cm}$, which is a $3 \%$ error and is acceptable.

After the experiment starts, the reading of interface line $A B$ does not show significant changes, while the reading of interface line $C D$ increases from $2.4 \mathrm{~cm}$ to $3.6 \mathrm{~cm}$, as is shown in Figure $4 \mathrm{~b}$. The dotted line in Figure $4 \mathrm{~b}$ is the original position of line $\mathrm{CD}$ before experiment, and the solid line is the position at $3.466 \mathrm{~s}$. The rising reading of the interface line $C D$ indicates that the surface of sediment rises up, which was also observed by Sumer et al. (2001). According to Sumer et al. (2001), the rise of the sand bed can be attributed to the increase of seepage force on the sand grains on the downstream side of the pipeline due to the pressure difference on two sides of the pipeline powered by the unidirectional current.

In Figure $4 \mathrm{c}$, the sand around point $\mathrm{G}$ on the downstream side of the pipeline starts to float due to the excessive seepage force, and the range of flotation expands (Fig. 4d). The sand near point G gradually reaches the critical point of onset of scour. In less than one second, the sand on the downstream side of the pipeline breaks up, and a mixture of sand and water surges out (Fig. 4e). This phenomenon is also reported by Sumer et al. (2001). Soon after, sand flotation and onset of scour also shows up at an adjacent point, point $\mathrm{H}$ (Figs 4f, g) while the failure zone on the section near point $G$ swiftly expands to the upstream side of the pipeline and initial scour hole is formed. In Figures 4e-g, it is observable that the onset of scour starts from the downstream side of the pipeline and the failure of soil expands from the downstream side to the upstream side, instead of starting at the same time on the section of the pipeline.

At last, the whole part of the pipeline in the camera view suffers the onset of scour due to several simultaneous failure points along the pipeline, and the pipeline span happens (Fig. 4h).

\subsection{Process of the partial scour pattern}

The partial scour pattern takes place in the rest cases. Figure 5 shows the scour process of recorded in case 201. As is shown in Figure 5a, the sand grain in the circle on the downstream side of the pipeline reaches the critical point of onset of scour and the initial scour hole is soon formed here (see Fig. 5b). The reading of interface line $\mathrm{CD}$ on the downstream side of the pipeline does not show any significant changes before the onset of scour. As is depicted in Table 2, the pipeline embedment in this case is also $0.5 \mathrm{~cm}$, so the readings of line CD should be 2.36 $\mathrm{cm}$ as well, like the case in section 3.1. The reading of interface line CD is about $2.5 \mathrm{~cm}$ in Figure 5a, which is quite close to the theoretical value. This means that the sediment surface on the downstream side does not rise up and this phenomenon continues later in the whole scour process under the pipeline (See Figs 5b-d).

After the onset of scour, the scour hole extends along the pipeline. When the flow enters the scour hole, the current is bound with the pipeline, the span shoulder and the sediment bed and thus the velocity increases dramatically. The increase of flow velocity leads to the rise of shear stress in the bed. The increased shear stress triggers the motion of the sediment on the span shoulder and on the bottom of the scour hole and intensifies the scour in these areas. As time goes by, the scour hole extends along the pipeline (Figs 5c-d). 

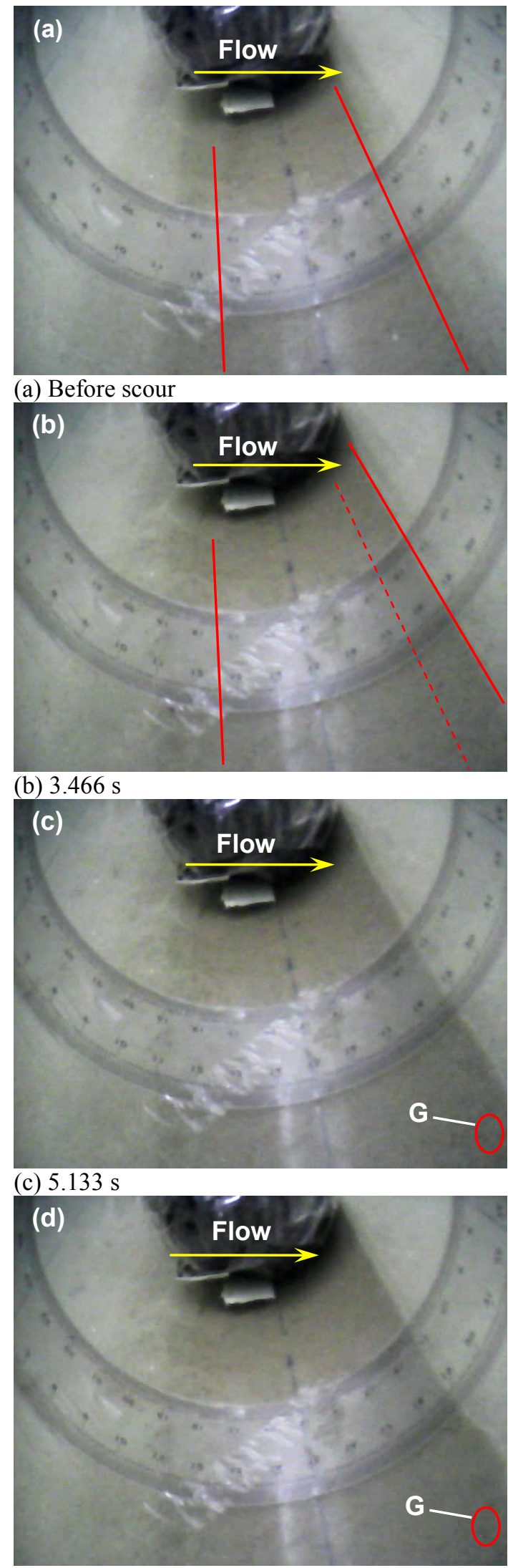

(d) $5.667 \mathrm{~s}$
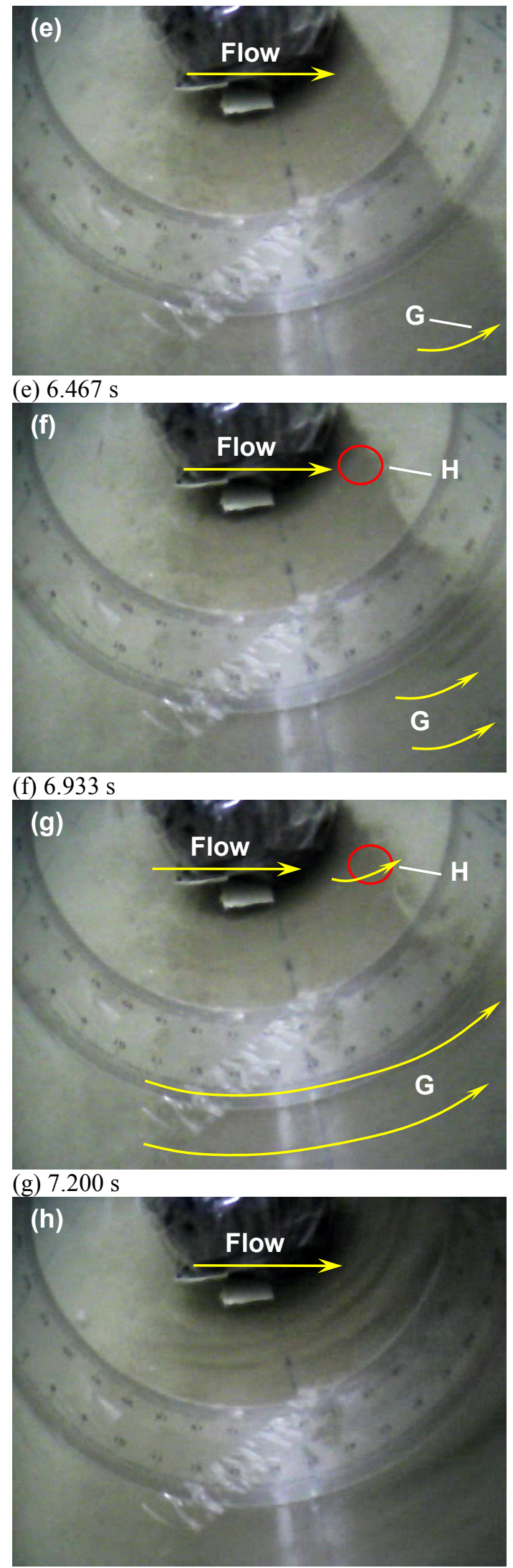

(h) $8.867 \mathrm{~s}$

Figure 4. Process of integral scour pattern 


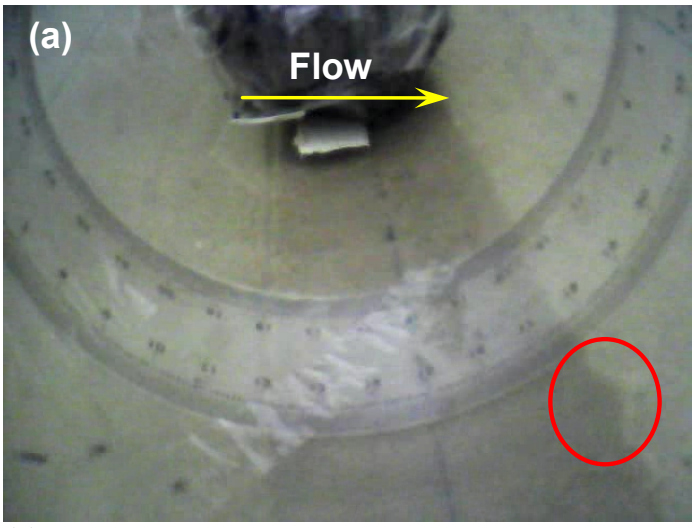

(a) $3.133 \mathrm{~s}$

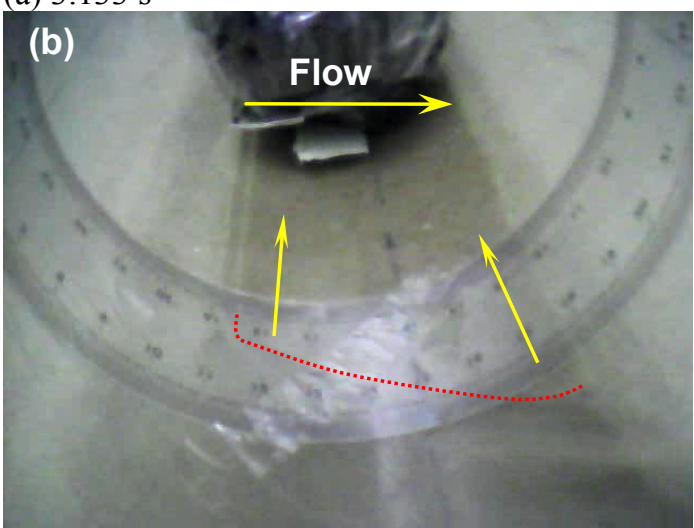

(b) $6.867 \mathrm{~s}$

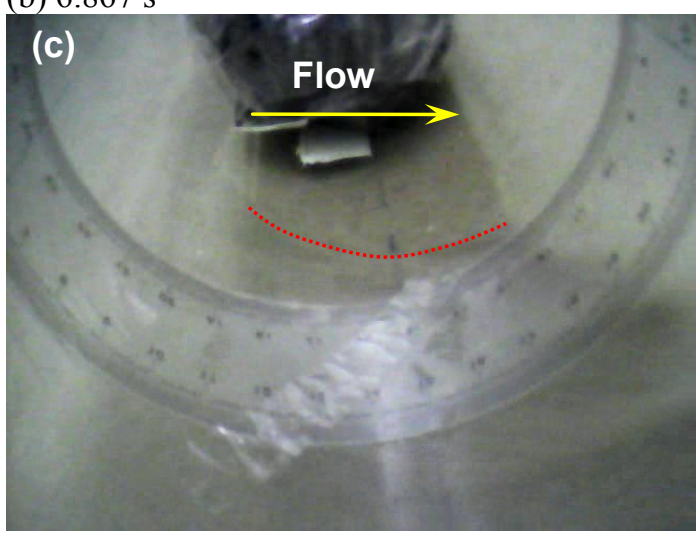

(c) $12.133 \mathrm{~s}$

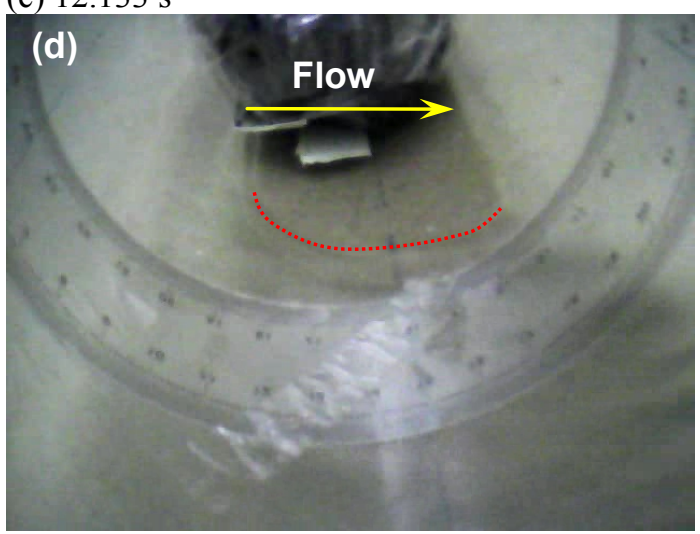

(d) $13.200 \mathrm{~s}$

Figure 5. Process of partial scour pattern

\subsection{Analysis on the scour patterns}

According to the description and analysis above, the excessive hydraulic gradient due to the pressure difference on two sides of the pipeline is the attribution to the onset of scour in both the initial and partial scour patterns. The major difference between the two patterns lies in the driving power for the scour hole expansion process. In the integral scour pattern, this process is still driven by the hydraulic gradient, while in the partial scour pattern the dominant force of the scour expansion is the bed shear stress.

In the integral scour pattern, the seepage force powered by the significant hydraulic gradient is high enough to trigger many separate failure points within a short distance along the downstream side of the pipeline almost simultaneously. The downstream interface of sediment bed and the pipeline also rises up due to the excessive hydraulic gradient. When the seepage failure points develop into initial scour holes, the sand grains adjacent to these points are all pushed out by the seepage force. Due to the short distance between the failure points, the sediment in a certain range along the pipeline is eroded in its entirety and a scour hole shows up in this range immediately after the onset of scour. So in the integral scour pattern, the whole scour process is mainly driven by the hydraulic gradient.

In the partial scour pattern, the hydraulic gradient is not as high as that in the integral pattern. Only a few failure points scatter on a long distance of the pipeline and the interface of sediment bed and the pipeline on the downstream side does not rise up. However, the process and mechanism of onset of scour in this pattern is very similar to those in the integral scour pattern. After the onset of scour, the sediment beneath the pipeline is divided into several span shoulders by the scour holes. When flow enters the scour hole, the current is restricted and the velocity increases significantly, as is mentioned above. The increase of flow velocity causes the increase of shear stress. Thus the sediment on the span shoulder and on the bed is scoured. So in the partial scour pattern, the onset of scour can be predominantly attributed to the hydraulic gradient, while the driving power for the scour hole expansion is the bed shear stress.

\section{PARAMETRIC ANALYSIS ON THE SCOUR HOLE CROSS-SECTION EXPANSION RATE}

Except for the scour patterns, the cross-section expansion rate of the scour hole is also influenced by the variation of the embedment to diameter ratio $e / D$, the relative flow depth $z_{0} / D$ and the depth averaged flow velocity $V_{0}$. In this section, the effects of 
these three parameters on the averaged scour hole cross-section expansion rate $v^{\prime} / V_{0}$ are considered.

\subsection{Analysis on the scour hole expansion process on cross section of pipeline}

Figure 6 shows a typical temporal development curve of the scour hole on the observed cross section. The length of scoured arc $l_{1}$ is used as the vertical axis in this graph. The curve is for case 210, where the pipeline embedment is $0.5 \mathrm{~cm}$, the flow depth is $40 \mathrm{~cm}$ and the depth averaged flow velocity is $0.3 \mathrm{~m} / \mathrm{s}$. The length of embedment arc is $4.72 \mathrm{~cm}$ in this case. As is shown in Figure 6, the expansion of scour hole on the cross section of the pipeline is non-linear. The curve can be approximately divided into two parts. The first 10 seconds of the scour process is the first part and the expansion of the scour hole on this cross section is almost linear. After that, the expansion rate significantly drops down and then starts a continuous increase. The expansion of scour hole on this cross section in last 10 seconds of the curve covers about half of the embedment arc. This phenomenon is also observed in many other cases.

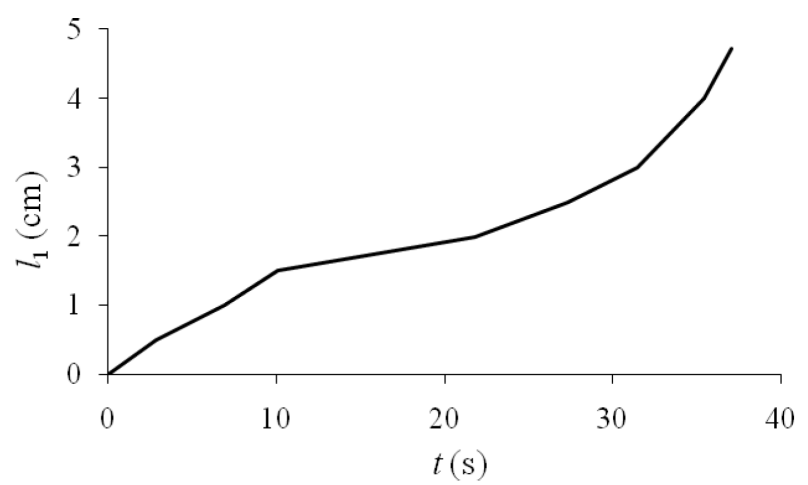

Figure 6. Temporal development of scour hole on pipeline cross section

\subsection{Effect of pipeline embedment}

Experiment group 1 focuses on the effect of pipeline embedment on the cross section expansion rate. In this group, both the relative flow depth $z_{0} / D$ and the depth averaged flow velocity $V_{0}$ are kept as constant $\left(z_{0} / D=2.73\right.$ and $\left.V_{0}=0.6 \mathrm{~m} / \mathrm{s}\right)$, while the embedment to diameter ratio $e / D$ varies between 0.045 and 0.182 . Figure 7 shows the relationship between the averaged expansion rate of the scour hole on the cross section $v^{\prime} / V_{0}$ and the pipeline embedment to diameter ratio $e / D$. In this diagram, for fixed value of $z_{0} / D$ and $V_{0}, v^{\prime} / V_{0}$ decreases with the increase of $e / D$ in an approximate linear way.

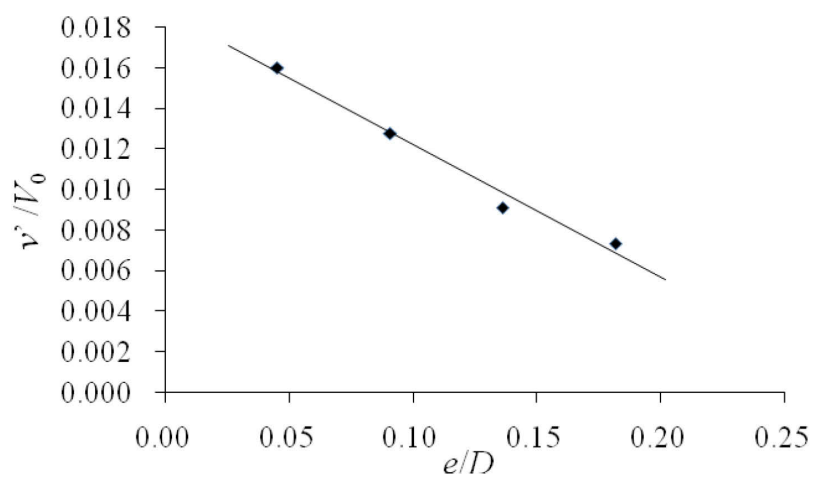

Figure 7. Averaged expansion rate of the scour hole on the cross section $v^{\prime} / V_{0}$ versus embedment to diameter ratio $e / D$ for $z_{0} / D=2.73$ and $V_{0}=0.6 \mathrm{~m} / \mathrm{s}$

Reports from Hansen et al. (1991) and Cheng et al. (2009) indicate a similar trend with the results above that the scour hole expansion rate on the longitudinal direction (along the axis of the pipeline) also decreased with the increase of pipeline embedment. The results of Hansen et al. (1991) show that the decrease of longitudinal scour propagation rate with increasing $e / D$ is almost linear for a range of Shields number when $e / D \leq 0.2$, while those from Cheng et al. (2009) show an approximate linear trend that the longitudinal scour propagation rate decreases with the increasing $e / D$ when $e / D \leq 0.5$.

\subsection{Effect of flow depth}

Experiment group 2 focuses on the effect of flow depth on the cross section expansion rate. In this group, both the embedment to diameter ratio $e / D$ and the depth averaged flow velocity $V_{0}$ are kept as constant $\left(e / D=0.045\right.$ and $\left.V_{0}=0.4 \mathrm{~m} / \mathrm{s}\right)$, while the relative flow depth $z_{0} / D$ varies between 2.73 and 5.45. Figure 8 shows the relationship between the averaged cross section expansion rate of the scour hole $v^{\prime} / V_{0}$ and the relative flow depth $z_{0} / D$. In this diagram, for fixed value of $e / D$ and $V_{0}, v^{\prime} / V_{0}$ decreases with the increase of $z_{0} / D$. Wu and Chiew (2010) also reported a similar trend of scour hole propagation along the pipeline axis to the flow depth.

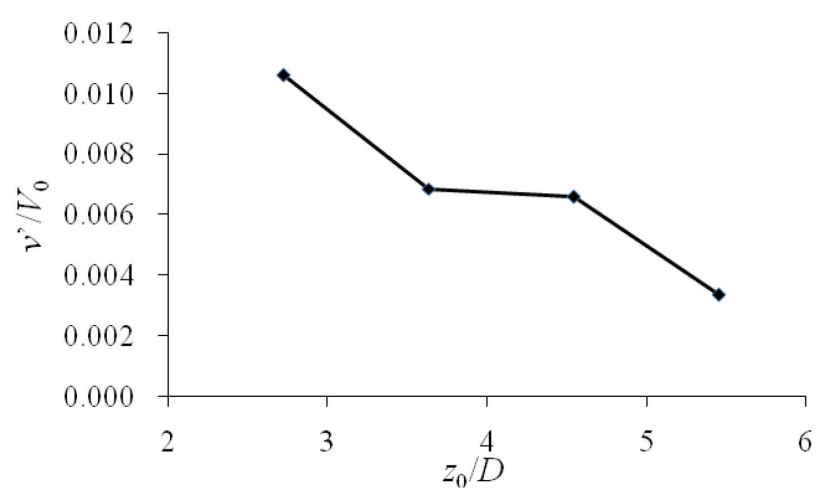

Figure 8. Averaged expansion rate of the scour hole on the cross section $v^{\prime} / V_{0}$ versus relative flow depth $z_{0} / D$ for $e / D=$ 0.045 and $V_{0}=0.4 \mathrm{~m} / \mathrm{s}$ 


\subsection{Effect of depth averaged flow velocity}

Experiment group 3 focuses on the effect of the depth averaged flow velocity on the cross section expansion rate. In this group, both the embedment to diameter ratio $e / D$ and the relative flow depth $z_{0} / D$ are kept as constant $\left(e / D=0.045\right.$ and $\left.z_{0} / D=3.64\right)$, while the depth averaged flow velocity $V_{0}$ varies between $0.2 \mathrm{~m} / \mathrm{s}$ and $0.6 \mathrm{~m} / \mathrm{s}$. Figure 9 shows the relationship between the averaged cross section expansion rate of the scour hole $v^{\prime} / V_{0}$ and the depth averaged flow velocity $V_{0}$. In this diagram, for fixed value of $e / D$ and $z_{0} / D, v^{\prime} / V_{0}$ increases steadily with the increase of $V_{0}$.

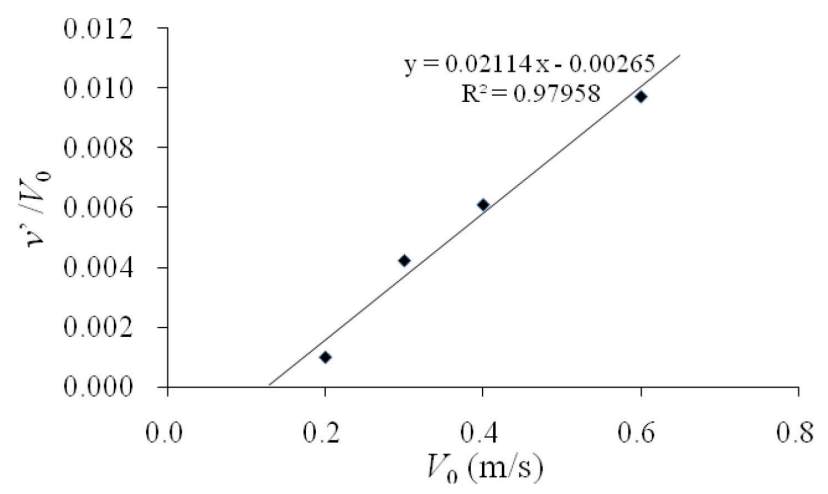

Figure 9. Averaged expansion rate of the scour hole on the cross section $v^{\prime} / V_{0}$ versus depth averaged flow velocity $V_{0}$ for $e / D=0.045$ and $z_{0} / D=3.64$

In addition, the $\mathrm{x}$ intercept of the linear fitting function bears some physical implication. When $v^{\prime} / V_{0}=0$, which means that the scour hole is on a critical point of expansion, the value of the flow velocity is the critical velocity of scour hole expansion

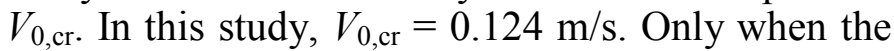
flow velocity is above this critical value, does the scour hole start to expand along the pipeline. It should be noted that this critical value varies with parameters like the pipeline embedment and the flow depth and it can be smaller than the velocity for the incipient motion, for the expansion of the scour hole is determined by the velocity around the span shoulder and in the scour hole, not directly by the depth averaged flow velocity.

\section{CONCLUSIONS}

The following conclusions can be drawn from the aforementioned results in this study.

1 The scour process beneath the pipeline can be divided into an integral scour pattern and a partial scour pattern within the tested ranges of the three parameters, namely the pipeline embedment, the flow depth and the approach flow velocity.

2 In the integral scour pattern, the whole scour process, from the onset of scour to the scour hole expansion, is mainly driven by the hydraulic gradient.
3 In the partial scour pattern, the onset of scour can be predominantly attributed to the hydraulic gradient, while the driving power for the scour hole expansion is the bed shear stress.

4 The scour hole cross-section expansion rate decreases with the increase of pipeline embedment and flow depth and increases with the increase of flow velocity.

5 The $\mathrm{x}$ intercept of the flow velocity - crosssection expansion rate curve indicates a critical velocity of scour hole expansion $V_{0, \text { cr }}$. Only when the flow velocity is above this critical value, does the scour hole start to expand along the pipeline.

\section{REFERENCES}

BIJKER, R., STAUB, C., SILVIS, F. \& BRUSCHI, R. Scourinduced free spans. Offshore Technology Conference, 1991. Offshore Technology Conference.

CHEN, B. \& CHENG, L. Numerical investigation of threedimensional flow around a free-spanned pipeline. The Twelfth International Offshore and Polar Engineering Conference, 2002. International Society of Offshore and Polar Engineers.

CHENG, L., YEOW, K., ZHANG, Z. \& TENG, B. 2009. Three-dimensional scour below offshore pipelines in steady currents. Coastal Engineering, 56, 577-590.

CHENG, L. \& ZHAO, M. Numerical Model for ThreeDimensional Scour below a Pipeline in Steady Currents. International Conference on Scour and Erosion (ICSE-5) 2010 San Francisco. ASCE, 482-490.

CHIEW, Y. 1990. Mechanics of Local Scour Around Submarine Pipelines. Journal of Hydraulic Engineering, 116, 515529.

GAO, F. P. \& LUO, C. C. 2010. Flow-Pipe-Seepage Coupling Analysis of Spanning Initiation of a Partially-Embedded Pipeline. Journal of Hydrodynamics Ser B, 22, 478-487.

HANSEN, E. A., Staub, C., Fredsøe, J., \& Sumer, B. M. 1991. Time-development of scour induced free spans of pipelines. Proceedings of the 10th conference on offshore mechanics and arctic engineering, Stavanger, Norway, Vol. V, ASME, New York, 25-31.

KAZEMINEZHAD, M. H., YEGANEH-BAKHTIARY, A., ETEMAD-SHAHIDI, A. \& BAAS, J. H. 2012. Two-Phase Simulation of Wave-Induced Tunnel Scour beneath Marine Pipelines. Journal of Hydraulic Engineering-Asce, 138, 517-529.

QIU, D. 1999. Engineering hydrology, Beijing, China Communications Press. (In Chinese)

RAAIJMAKERS, T., VAN VELZEN, G. \& RIEZEBOS, H. J. Dynamic scour prediction for offshore monopiles - validation against laboratory and field measurements. Scour and Erosion: Proceedings of the 7th International Conference on Scour and Erosion, Perth, Australia, 2-4 December 2014, 2014. CRC Press, 813.

SHEN, W., GRIFFITHS, T., XU, M. \& LEGGOE, J. 2D and 3D CFD Investigations of Seabed Shear Stresses around Subsea Pipelines. ASME 2013 32nd International Conference on Ocean, Offshore and Arctic Engineering, 2013. ASME, V04AT04A048-V04AT04A048.

SHEN, W., GRIFFITHS, T., ZAN, Z. \& LEGGOE, J. Shear stress amplification around subsea pipelines: Part 3, 3D study of spanning pipelines. Scour and Erosion: Proceedings of the 7th International Conference on Scour and Ero- 
sion, Perth, Australia, 2-4 December 2014, 2014. CRC Press, 325-335.

SUMER, B. M., TRUELSEN, C., SICHMANN, T. \& FREDSOE, J. 2001. Onset of scour below pipelines and selfburial. Coastal Engineering, 42, 313-335.

WU, Y. \& CHIEW, Y. Three-Dimensional Scour at Submarine Pipelines in Unidirectional Steady Current. International Conference on Scour and Erosion (ICSE-5), 2010 San Francisco. ASCE, 471-481.

WU, Y. \& CHIEW, Y. 2013. Mechanics of Three-Dimensional Pipeline Scour in Unidirectional Steady Current. Journal of Pipeline Systems Engineering and Practice, 4, 3-10.

YEGANEH-BAKHTIARY, A., KAZEMINEZHAD, M. H., ETEMAD-SHAHIDI, A., BAAS, J. H. \& CHENG, L. 2011. Euler-Euler two-phase flow simulation of tunnel erosion beneath marine pipelines. Applied Ocean Research, 33, 137-146.

YEGANEH-BAKHTIARY, A., ZANGANEH, M., KAZEMI, E., CHENG, L. \& WAHAB, A. K. A. 2013. EulerLagrange Two-Phase Model for Simulating Live-Bed Scour Beneath Marine Pipelines. Journal of Offshore Mechanics \& Arctic Engineering, 135, 1885-1886.

ZANG, Z., CHENG, L., ZHAO, M., LIANG, D. \& TENG, B. 2009. A numerical model for onset of scour below offshore pipelines. Coastal Engineering, 56, 458-466.

ZHOU, C., LI, G., DONG, P., SHI, J. \& XU, J. 2011. An experimental study of seabed responses around a marine pipeline under wave and current conditions. Ocean Engineering, 38, 226-234. 